\title{
Baicalein protects HT22 murine hippocampal neuronal cells against endoplasmic reticulum stress-induced apoptosis through inhibition of reactive oxygen species production and CHOP induction
}

\author{
Ji Hyun Choi ${ }^{1}$, A Young Choi ${ }^{1}$, Hana Yoon ${ }^{1}$, \\ Wonchae Choe', Kyung-Sik Yoon ${ }^{1}$, Joohun $\mathrm{Ha}^{1}$, \\ Eui-Ju Yeo ${ }^{2,3}$ and Insug Kang ${ }^{1,3}$ \\ ${ }^{1}$ Department of Biochemistry and Molecular Biology \\ School of Medicine \\ Medical Science and Engineering Research Center \\ for Bioreaction to Reactive Oxygen Species \\ Biomedical Science Institute \\ Kyung Hee University \\ Seoul 130-701, Korea \\ 2Department of Biochemistry \\ Gachon University of Medicine and Science \\ Incheon 406-799, Korea \\ ${ }^{3}$ Corresponding authors: Tel, 82-2-961-0922; \\ Fax, 82-2-965-6349; E-mail, iskang @ khu.ac.kr (I.K.) \\ Tel, 82-32-820-4742; Fax, 82-32-820-4744; \\ E-mail, euiju@gachon.ac.kr (E.J.Y.) \\ DOI 10.3858/emm.2010.42.12.084
}

Accepted 14 October 2010

Available Online 18 October 2010

Abbreviations: ATF6, activating transcription factor 6; BFA, brefeldin A; CHOP, C/EBP homologous protein; DCF-DA, 2',7'-dichlorofluorescein diacetate; $\mathrm{DiOC}_{6}, 3,3$ '-dihexyloxacarbocyanine iodide; elF2 $\alpha$, eukaryotic initiation factor $2 \alpha$; ER, endoplasmic reticulum; GRP78, glucose-regulated protein 78; MMP, mitochondrial membrane potential; NAC, N-acetyl cysteine; PARP, poly(ADP-ribose) polymerase; PERK, PKR-like endoplasmic reticulum kinase; PI, propidium iodide; ROS, reactive oxygen species; TG, thapsigargin; XBP-1, $\mathrm{X}$-box binding protein-1

\begin{abstract}
Baicalein is one of the major flavonoids in Scutellaria baicalensis Georgi and possesses various effects, including cytoprotection and anti-inflammation. Because endoplasmic reticulum (ER) stress has been implicated in neurodegenerative diseases, such as Alzheimer's disease, Parkinson's disease, and cerebral ischemia, we investigated the effects of baicalein on apoptotic death of HT22 mouse hippocampal neuronal cells induced by thapsigargin (TG) and brefeldin A
\end{abstract}

(BFA), two representative ER stress inducers. Apoptosis, reactive oxygen species (ROS) production, and mitochondrial membrane potential (MMP) were measured by flow cytometry. Expression level and phosphorylation status of ER stress-associated proteins and activation and cleavage of apoptosis-associated proteins were analyzed by Western blot. Baicalein reduced TG- and BFA-induced apoptosis of HT22 cells and activation and cleavage of apoptosis-associated proteins, such as caspase-12 and -3 and poly(ADP-ribose) polymerase. Baicalein also reduced the TG- and BFA-induced expression of ER stress-associated proteins, including C/EBP homologous protein (CHOP) and glucose-regulated protein 78 , the cleavage of $\mathrm{X}$-box binding protein-1 and activating transcription factor $6 \alpha$, and the phosphorylation of eukaryotic initiation factor- $2 \alpha$ and mitogen-activated protein kinases, such as p38, JNK, and ERK. Knock-down of CHOP expression by siRNA transfection and specific inhibitors of p38 (SB203580), JNK (SP600125), and ERK (PD98059) as well as anti-oxidant ( $\mathrm{N}$-acetylcysteine) reduced TG- or BFA-induced cell death. Baicalein also reduced TG- and BFA-induced ROS accumulation and MMP reduction. Taken together, these results suggest that baicalein could protect $\mathrm{HT} 22$ neuronal cells against ER stress-induced apoptosis by reducing CHOP induction as well as ROS accumulation and mitochondrial damage.

Keywords: apoptosis; baicalein; brefeldin A; endoplasmic reticulum; reactive oxygen species; thapsigargin

\section{Introduction}

Baicalein (5,6,7-trihydroxy-2-phenyl-4H-1-benzopyran-4-one) is one of the effective flavonoids found in Scutellaria baicalensis Georgi, which has been widely used in the traditional herbal medicine against various inflammatory diseases and ischemia (Kim et al., 2001). Baicalein's cytoprotective and anti-inflammatory actions are based upon radical quenching and anti-oxidative effects (Gao et al., 1999; Shao et al., 2002; Hwang et al., 2008; 
Jung et al., 2008). Baicalein also exerts proapoptotic activity through reactive oxygen species (ROS)-mediated and $\mathrm{Ca}^{2+}$-dependent mitochondrial dysfunction pathways in various cell types (Wong et al., 2001; Chang et al., 2002; Pidgeon et al., 2002; Wang et al., 2004).

Endoplasmic reticulum (ER) stress-coupled apoptotic cell death has been implicated in many diseases, including diabetes and a variety of neurodegenerative disorders including Alzheimer's disease, Parkinson disease, and cerebral ischemia (Boyce and Yuan, 2006; Lindholm et al., 2006; Kim et al., 2008; Arduino et al., 2009; Lee et al., 2010). ER stress activates specific signaling pathways (Breckenridge et al., 2003; Schroder and Kaufman, 2005), in a process known as the unfolded protein response (Kaufman, 1999; Malhotra and Kaufman, 2007; Cho et al., 2009), which includes phosphorylation of eukaryotic initiation factor $2 \alpha$ (elF2 $\alpha$ ) by the activated PKR-like endoplasmic reticulum kinase (PERK) (Harding et al., 2000; Boyce et al., $2005)$, cleavage of the X-box binding protein-1 (XBP-1) mRNA by the activated inositol-requiring enzyme 1, which translocates to the nucleus and regulates expression of ER chaperone genes, such as glucose-regulated protein 78 (GRP78) (Tirasophon et al., 1998; Calfon et al., 2002), and cleavage of activating transcription factor 6 (ATF6) by proteases, such as S1P and S2P in the Golgi, which regulates expression of ER stress-target genes, such as C/EBP homologous protein (CHOP) and XBP-1 (Yoshida et al., 2001).

When ER functions are severely impaired, apoptosis occurs to protect the organism by elimination of damaged cells (Oyadomari and Mori, 2004). CHOP participates in ER stress-mediated apoptosis (Zinszner et al., 1998; Szegezdi et al., 2006), presumably by suppression of $\mathrm{Bcl}-2$ activation. In addition to $\mathrm{CHOP}$, the mitogen-activated protein kinases (MAPKs), such as p38, c-Jun NH2terminal kinase (JNK), and extracellular-regulated kinase (ERK), were also activated by ER stress inducers and played an important role in apoptosis (Wang and Ron, 1996; Urano et al., 2000; Arai et al., 2004; Yang et al., 2007). ER stress also induces mitochondrial dysfunction, caspase activation, and apoptosis through organelle crosstalk between the ER and mitochondria (Rao et al., 2001; Hitomi et al., 2004; Arduino et al., 2009). Caspase-12, localized in the ER, and caspase-3, a common cell death effector, are cleaved and activated, which results in pro-apoptotic actions of ER stress (Schroder and Kaufman, 2005; Kim et al., 2006; Szegezdi et al., 2006).

Because baicalein could exert both anti- and pro-apoptotic activities depending on the condi- tions and cell types, we examined the effect of baicalein on ER stress-induced cell death in HT22 murine hippocampal neuronal cells. To further study the action mechanism of baicalein involved in neuroprotection, we monitored its effects on ER stress-associated proteins including expression of CHOP and GRP78, phosphorylation of elF2 $\alpha$ and MAPKs, accumulation of ROS, and reduction of mitochondrial membrane potential (MMP) induced by two ER stress inducers, thapsigargin (TG) and brefeldin A (BFA).

\section{Results}

\section{Baicalein protects HT22 hippocampal neuronal cells against TG- and BFA-induced cell death}

To identify phytochemicals capable of exerting neuronal protection against ER stress, we investigated the effects of baicalein on ER stress-induced cell death in the murine hippocampal neuronal cell line HT22, which is known to phenotypically resemble neuronal precursor cells. To accomplish this, HT22 cells were preincubated with various concentrations of baicalein for $1 \mathrm{~h}$, and then treated with ER stress inducers, $5 \mu \mathrm{M}$ TG or $10 \mu \mathrm{M}$ BFA, for $24 \mathrm{~h}$. Cell viability was then measured by MTT assay and the percent cell viabilities were plotted (Figure 1A). Treatment with TG and BFA reduced the percent cell viability by about $70 \%$. Pretreatment with baicalein at concentrations ranging from 10-50 $\mu \mathrm{M}$ reduced TGand BFA-induced cell death in a dose-dependent manner (Figure 1A). These results suggest that baicalein protects HT22 hippocampal neuronal cells against ER stress-induced cell death.

Because we observed that TG and BFA induced morphologic changes of apoptotic cell death in HT22 cells (data not shown), we investigated the effects of baicalein on TG- and BFA-induced apoptosis. Apoptotic cell death was monitored by flow cytometric analysis of sub-G1 DNA, which was believed to be apoptotic DNA (Telford et al., 1992). After $24 \mathrm{~h}$ of incubation with $5 \mu \mathrm{M}$ TG or 10 $\mu \mathrm{M}$ BFA in the absence of baicalein, the sub-G1 fraction increased from $6.95 \%$ to $63.84 \%$ and $55.27 \%$, respectively (Figure 1B and 1C). Baicalein alone increased the percent sub-G1 fraction from $6.95 \%$ to $9.79 \%$; however, baicalein pretreatment at $50 \mu \mathrm{M}$ attenuated TG-induced sub-G1 fractions from $63.84 \%$ to $28.96 \%$, and BFA-induced sub-G1 fractions from $55.27 \%$ to $26.20 \%$ (Figure $1 \mathrm{~B}$ and $1 \mathrm{C})$, suggesting that baicalein could protect HT22 neuronal cells against ER stress-induced apoptotic death. By contrast, baicalin, the predominant flavone glycoside in the root of Scutellaria baicalensis, 


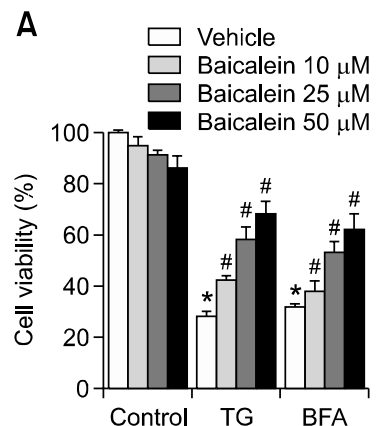

C

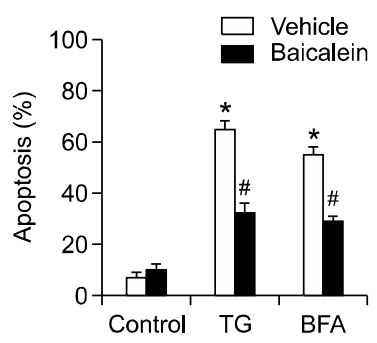

B

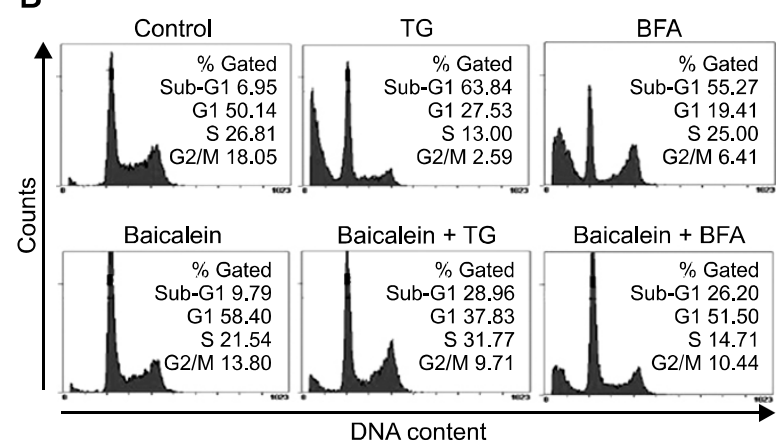

Figure 1. Effects of baicalein on ER stress-induced apoptosis in HT22 hippocampal neuronal cells. (A) HT22 cells were pretreated with vehicle or various concentrations of baicalein for $1 \mathrm{~h}$, and treated with vehicle (Control), $5 \mu \mathrm{M} \mathrm{TG}$, or $10 \mu \mathrm{M}$ BFA for $24 \mathrm{~h}$. The cell viability was then determined by MTT assay and the percent cell viabilities were plotted as the means \pm standard deviation of at least three experiments. ${ }^{*} P$ 0.01 when compared with untreated control cells. ${ }^{\#} P<0.01$ when compared with TG- or BFA-treated cells without baicalein. (B) Cells were preincubated with $50 \mu \mathrm{M}$ baicalein for $1 \mathrm{~h}$, and treated with vehicle (Control), $5 \mu \mathrm{M} \mathrm{TG}$, or $10 \mu \mathrm{M}$ BFA for $24 \mathrm{~h}$, stained with PI, and then evaluated by flow cytometry. The first peak (sub-G1) represents apoptotic cells with a lower DNA content. (C) Cells were preincubated with $50 \mu \mathrm{M}$ baicalein for $1 \mathrm{~h}$, and treated with vehicle (Control), $5 \mu \mathrm{M} \mathrm{TG}$, or $10 \mu \mathrm{M}$ BFA for $24 \mathrm{~h}$, stained with $\mathrm{PI}$, and then evaluated by flow cytometry. The percent apoptotic sub-G1 fractions were plotted as the means \pm standard deviation of at least three experiments. ${ }^{*} P<0.01$ when compared with untreated control cells. ${ }^{\sharp} P<0.01$ when compared with TG- or BFA-treated cells without baicalein.

showed no protective effect against TG- or BFAinduced HT22 cell apoptosis at the same concentration (data not shown). Similar to its effect on apoptotic cell death of HT22, baicalein inhibited TG- or BFA-induced apoptosis in N2A mouse neuroblastoma cells (data not shown).

\section{Baicalein inhibits the cleavage of caspase-12/-3 and poly(ADP-ribose) polymerase}

Previous studies have shown that caspase-12 and caspase- 3 are cleaved and activated, which results in pro-apoptotic actions of ER stress (Schroder and Kaufman, 2005; Kim et al., 2006; Szegezdi et al.,
2006). Therefore, baicalein-treated cells were evaluated by Western blot analysis to determine whether baicalein treatment affects the cleavage and activation of caspases. HT22 cells were preincubated with $50 \mu \mathrm{M}$ baicalein for $1 \mathrm{~h}$ and then treated with $5 \mu \mathrm{M}$ TG (Figure $2 \mathrm{~A}$ ) or $10 \mu \mathrm{M}$ BFA (Figure 2B) for 2-24 h. Results showed that TG and BFA increased the cleavage of caspase-12 and -3 , while baicalein reduced the cleaved forms of caspase-12 and -3. Activation of caspase- 3 is known to lead to cleavage of a number of proteins including poly(ADP-ribose) polymerase (PARP). Therefore, we also monitored the cleavage of intact 116-kDa PARP (F) to the cleaved $85-\mathrm{kDa}$ fragment PARP (C) by Western blot analysis. Consistent with its effect on activation and cleavage of caspase- 3 , baicalein inhibited PARP cleavage in TG- or BFA-treated cells. Taken together, these findings suggest that baicalein prevents ER stress-induced apoptosis via the reduction of caspase-12/-3 activation.

\section{Baicalein regulates unfolded protein responses}

Activation of caspase- 12 is closely related to ER stress-induced cell death. Because we found that baicalein inhibited ER stress-induced apoptotic cell death and activation of caspase-12 (Figure 2A and 2B), we examined whether baicalein affects expression of the pro-apoptotic ER stress protein $\mathrm{CHOP}$ as well as other unfolded protein responses such as GRP78 and the cleavage of XBP-1 and ATF6 $\alpha$ by Western blot analysis. The results showed that both TG (Figure $3 \mathrm{~A}$ ) and BFA (Figure $3 C$ ) induced expression of CHOP and GRP78 as well as cleavage of XBP-1 and ATF6 $\alpha$ at $6-24 \mathrm{~h}$, while baicalein abrogated these changes in HT22 cells.

We also examined whether or not baicalein influences TG- and BFA-induced initial unfolded protein responses including phosphorylation of elF2 $\alpha$ during the early period from $0.5-6 \mathrm{~h}$. TG and BFA increased phosphorylation of elF $2 \alpha$ at 1-6 h, while baicalein inhibited these early unfolded protein responses (Figure 3B and 3D). These results suggest that baicalein reversed TG- or BFA-induced ER stress signaling events, thereby protecting ER stress-induced cell death.

\section{Baicalein inhibits ER stress-induced activation of MAPKs such as p38, JNK, and ERK}

MAPKs, such as p38, JNK, and ERK, are activated and involved in ER stress-induced apoptosis (Wang and Ron, 1996; Arai et al., 2004; Yang et al., 2007). Therefore, we examined whether bai- 
A

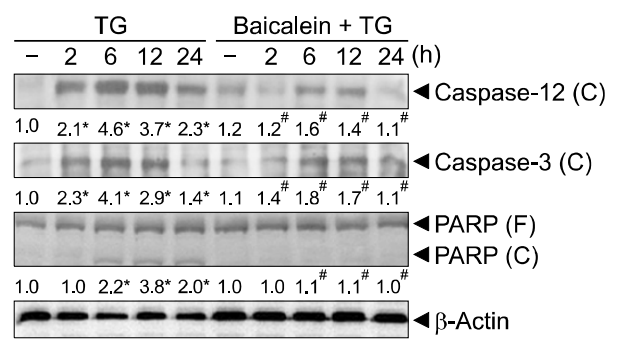

B

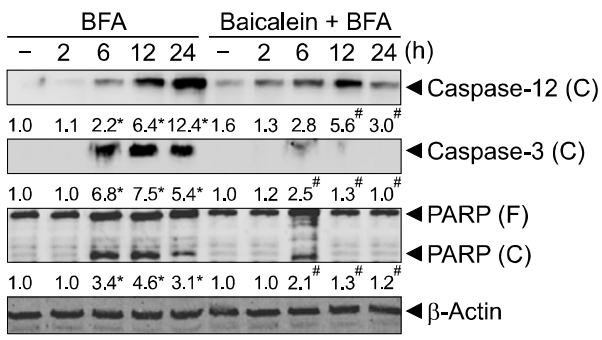

Figure 2. Effects of baicalein on ER stress-induced cleavage of caspase-12 and -3 and PARP in HT22 neuronal cells. HT22 cells were preincubated with $50 \mu \mathrm{M}$ baicalein for $1 \mathrm{~h}$ and then treated with $5 \mu \mathrm{M} \mathrm{TG}(\mathrm{A})$ or $10 \mu \mathrm{M}$ BFA (B) for the indicated times. Cells were lysed and the total cell extracts (50 $\mu \mathrm{g}$ per lane) were resolved by $10 \%$ SDS-PAGE. Protein levels of cleaved caspases- 12 and -3 and PARP were detected by Western blot analysis using antibodies specific to cleaved caspase-12 (cleaved, C), cleaved caspase-3 (cleaved, C), PARP (full, F; cleaved, C), and $\beta$-actin. The level of each cleaved protein was quantified by densitometry and normalized to the level of $\beta$-actin. Thereafter, the fold increase was calculated based on each data of vehicle (first lane). Results shown are representative of those obtained in more than three independent experiments. ${ }^{*} P<0.05$ when compared with untreated control cells. ${ }^{\sharp} P<0.05$ when compared with TG- or BFA-treated cells in the absence of baicalein at each incubation time.

calein regulates ER-stress-induced activation of MAPKs. Activation of MAPKs was monitored by examination of the level of phosphorylated MAPKs by Western blot analysis. As shown in Figure 4A and $4 \mathrm{~B}$, baicalein reduced TG- and BFA-induced phosphorylation of p38 and JNK, while baicalein had a small inhibitory effect on the phosphorylation of ERK.

To understand the involvement of MAPKs p38, JNK, and ERK in TG- or BFA-induced cell death, cells were pretreated with specific inhibitors of p38 (10 $\mu \mathrm{M}$ SB203580), JNK (10 $\mathrm{MM}$ SP600125), and ERK (20 $\mu \mathrm{M}$ PD98059) followed by treatment with TG or BFA for $24 \mathrm{~h}$. We found that SB203580 and
A

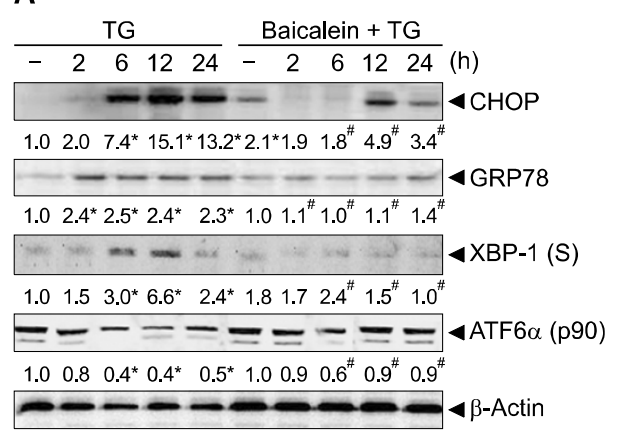

B

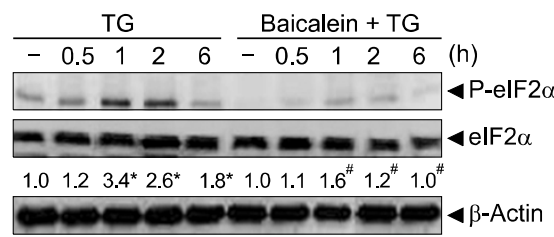

C

\begin{tabular}{|c|c|c|c|c|c|c|c|}
\hline \multicolumn{3}{|c|}{ BFA } & Baica & alein & $+\mathrm{B}$ & & \\
\hline- & $\begin{array}{lll}2 & 6 & 12\end{array}$ & 24 & -2 & 6 & 12 & 24 & (h) \\
\hline & -0 & - & $\cdots$ & $=$ & $=$ & $=$ & $4 \mathrm{CHOP}$ \\
\hline 1.0 & $1.07 .0^{*} 10.2$ & * $3.5^{*}$ & $\star \quad 1.21 .0$ & $2.5^{\#}$ & & $1.7^{\#}$ & \\
\hline$=$ & $\omega \cdots$ & - & 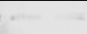 & $2=$ & 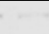 & & 4 GRP78 \\
\hline 1.0 & $6.2^{*} 8.3^{*} 7.2^{*}$ & $8.1^{*}$ & * $1.01 .1^{\#}$ & $\# 1.4^{\#}$ & $1.1^{\#}$ & $1.2^{\#}$ & \\
\hline$=$ & -- & $\rightarrow$ & - & - & 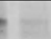 & & $4 \mathrm{XBP}-1(\mathrm{~S})$ \\
\hline 1.0 & $1.52 .7^{*} 3.0^{*}$ & $6.3^{*}$ & * 1.52 .0 & $2.2^{\#}$ & $1.4^{\#}$ & $1.1^{\#}$ & \\
\hline - & --- & & -- & - & - & - & 4 ATF $6 \alpha(p 90$ \\
\hline 1.0 & $\begin{array}{lll}1.4 & 1.3 & 0.4^{*}\end{array}$ & $0.3^{*}$ & * 1.51 .3 & 31.6 & $1.1^{\#}$ & $1.0^{\#}$ & \\
\hline
\end{tabular}

D

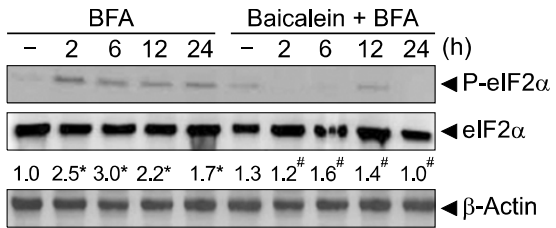

Figure 3. Effects of baicalein on expression of ER stress-associated proteins in HT22 neuronal cells. HT22 cells were treated with baicalein and TG (A and B) or BFA (C and D), as described in the legend for Figure 2. Cell lysates were resolved by $10 \%$ SDS-PAGE and then analyzed by Western blot using antibodies specific to CHOP, GRP78, spliced XBP-1 (spliced, S), ATF6 $\alpha$ (p90), phospho-elF2 $\alpha$ (P-elF2 $\alpha$ ), elF2 $\alpha$, and $\beta$-actin. The level of each protein was quantified by densitometry and normalized to the level of $\beta$-actin. The fold increase was calculated based on each data of vehicle (first lane). ${ }^{*} P<0.05$ when compared with untreated control cells. ${ }^{\sharp} P<0.05$ when compared with TG- or BFA-treated cells in the absence of baicalein at each incubation time. 
A

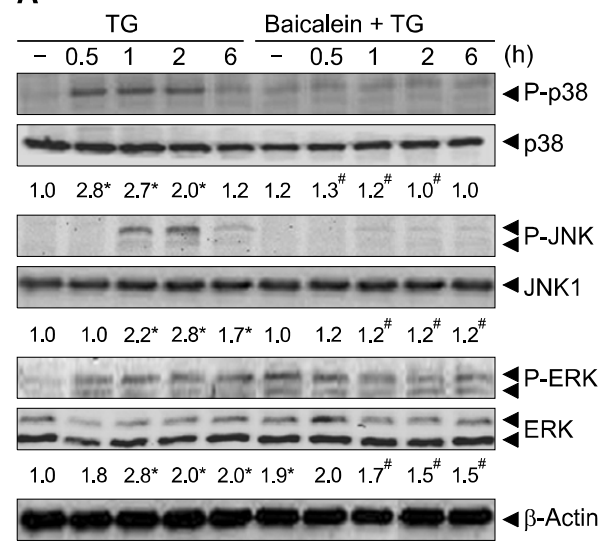

B

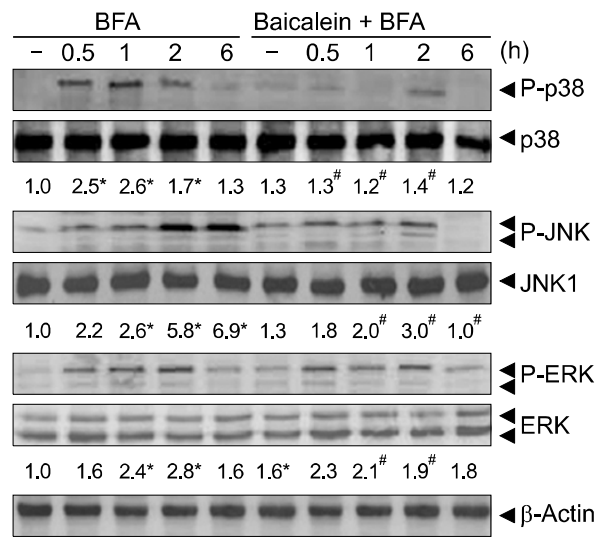

Figure 4. Effects of baicalein on ER stress-induced phosphorylation of $p 38$, JNK, and ERK in HT22 neuronal cells. HT22 cells were treated with baicalein and TG (A) or BFA (B) as described in the legend of Figure 2. Cell lysates were separated by $12 \%$ SDS-PAGE and then blotted onto nitrocellulose membranes. Protein levels of phosphorylated and total p38, JNK, and ERK were measured by Western blot analysis using antibodies specific to phospho-p38 (P-p38), p38, phospho-JNK (P-JNK), JNK1, phospho-ERK (P-ERK), ERK, and $\beta$-actin. The level of each phosphorylated protein was quantified by densitometry and normalized to the level of $\beta$-actin. Thereafter, the fold increase was calculated based on each data of vehicle (first lane). ${ }^{*} P<0.05$ when compared with untreated control cells. ${ }^{\#} P<0.05$ when compared with TG- or BFA-treated cells in the absence of baicalein at each incubation time.

SP600125 significantly $(P<0.01)$, and PD98059 less significantly $(P<0.05)$ reduced TG- and BFA-induced cell death (Figure 5A).

Using small interference RNA (siRNA) of CHOP, we also examined whether or not CHOP expression is involved in TG- or BFA-induced HT22 cell death. In agreement with the pro-apoptotic effect of CHOP (Zinszner et al., 1998; Szegezdi et al., 2006), knock-down of CHOP by siRNA transfection reduced TG- or BFA-induced cell death (Figure $5 \mathrm{~B}$ ). This suggests that $\mathrm{CHOP}$ plays a critical role in ER stress-induced cell death of HT22 cells. Similar to CHOP, caspase-12 is known to be involved in ER stress-induced apoptosis (Szegezdi et al., 2006) and baicalein reduces TG- or BFAinduced caspase-12 cleavage (Figure 2A and 2B). Therefore, we also examined the role of caspase12 in ER stress-induced cell death of HT22 cells. As expected, knock-down of caspase-12 by siRNA transfection reduced TG- or BFA-induced cell death (Figure $5 \mathrm{~B}$ ).

We next examined the effects of MAPKs on TGor BFA-induced CHOP expression in HT22 cells. We found that SP600125 and PD98059 reduced CHOP induction, whereas SB203580 had no effect on CHOP protein levels (Figure 5C and 5D). Because p38 was shown to induce CHOP transcriptional activation via its phosphorylation on serine residues (Wang and Ron, 1996), we examined whether TG or BFA induces CHOP phosphorylation on serine and SB203580 affects this phosphorylation. Cell lysates were immunoprecipitated with anti-CHOP antibody and the immunopre- cipitates were analyzed by Western blot using anti-phosphoserine antibody. The result showed that TG or BFA induced phosphorylation of CHOP on serine and SB203580 markedly inhibited this phosphorylation (Figure 5E). Collectively, these data suggest that baicalein could protect neuronal cells against apoptotic death through inhibition of ER stress-induced ERK as well as p38 and JNK activation.

\section{Baicalein reduces ER stress-induced ROS accumulation in HT22 neuronal cells}

Recent studies have shown the involvement of ROS in ER stress-induced apoptosis (Lee et al., 2007; Kim et al., 2008). ROS are also shown to mediate baicalein-induced ER stress in N18 mouse-rat hybrid retina ganglion cells ( $\mathrm{Li}$ et al., 2009). However, baicalein has been shown to have either anti-oxidant (Gao et al., 1999) or pro-oxidant effects (Wong et al., 2001; Chang et al., 2002; Pidgeon et al., 2002; Wang et al., 2004). Therefore, we examined the effects of baicalein on the accumulation of ROS in TG- or BFA-treated HT22 cells. Cells were preincubated with baicalein and treated with $5 \mu \mathrm{M}$ TG or $10 \mu \mathrm{M}$ BFA for the indicated times $(0.5-6 \mathrm{~h})$, and the cellular ROS levels were measured by flow cytometry using 2',7'-dichlorofluorescein diacetate (DCF-DA) staining. As shown in Figure 6A, TG or BFA induced ROS accumulation as early as $30 \mathrm{~min}$ after treatment. Although baicalein alone induced ROS accumulation, indicating its pro-oxidant effect, it 

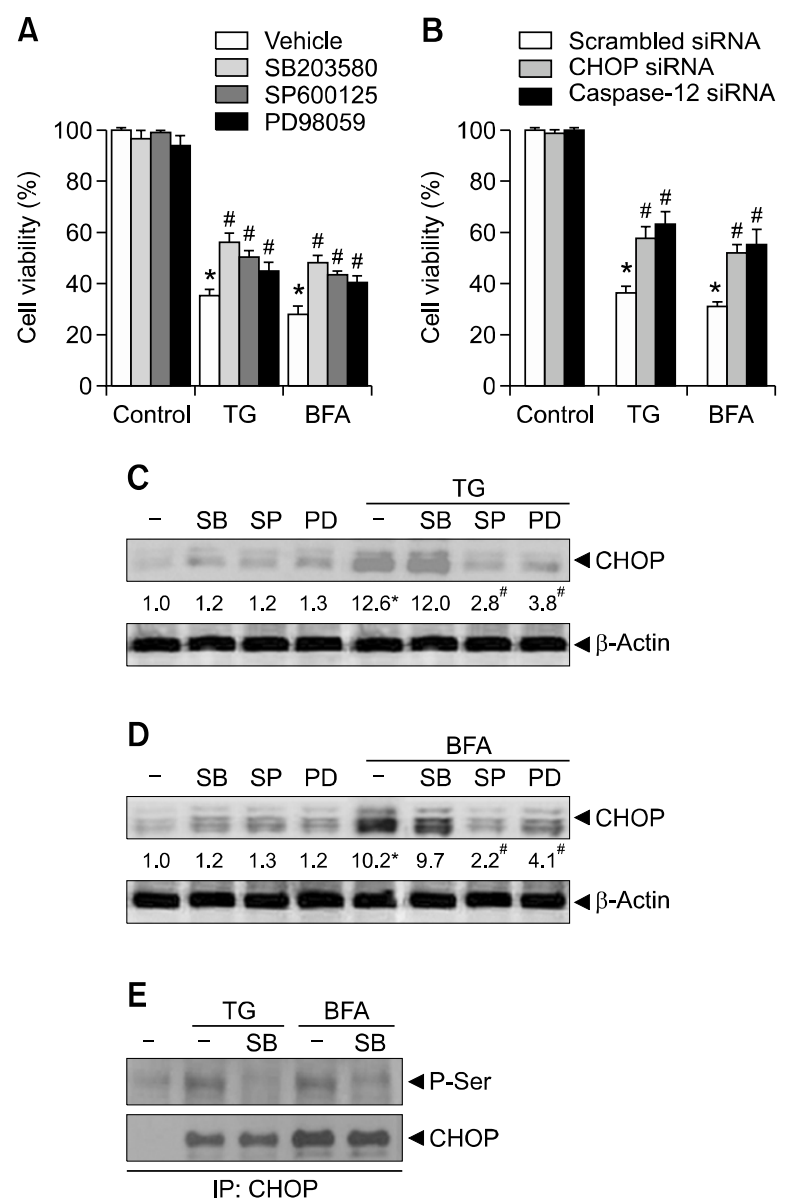

Figure 5. Effects of inhibitors of MAPKs and siRNAs for CHOP and caspase 12 on ER stress-induced cell death and CHOP expression and phosphorylation in HT22 neuronal cells. (A) HT22 cells were pretreated with vehicle or inhibitors of MAPKs (10 $\mu \mathrm{M} \mathrm{SB203580}$ for p38, $10 \mu \mathrm{M}$ SP600125 for JNK, $20 \mu \mathrm{M}$ PD98059 for ERK) for $1 \mathrm{~h}$, and treated with vehicle (Control), $5 \mu \mathrm{M} \mathrm{TG}$, or $10 \mu \mathrm{M}$ BFA for $24 \mathrm{~h}$. Cell viability was then determined by MTT assay. ${ }^{*} P<0.01$ when compared with untreated control cells. ${ }^{\#} P<0.01$ when compared with TG- or BFA-treated cells without inhibitors. (B) HT22 cells were transfected with $\mathrm{CHOP}$, caspase-12, and control scrambled siRNAs for $24 \mathrm{~h}$ and treated with TG or BFA for $24 \mathrm{~h}$. Cell viability was then determined by MTT assay. ${ }^{*} P<$ 0.01 when compared with untreated control cells. ${ }^{\#} P<0.01$ when compared with TG- or BFA-treated cells with scrambled siRNA transfection. (C, D) Cells were pretreated with $10 \mu \mathrm{M}$ SB203580 (SB), $10 \mu \mathrm{M}$ SP600125 (SP), or $20 \mu \mathrm{M}$ PD98059 (PD) for $1 \mathrm{~h}$, and treated with vehicle, $5 \mu \mathrm{M}$ TG (C), or $10 \mu \mathrm{M}$ BFA (D) for $24 \mathrm{~h}$. Cell lysates were separated by SDS-PAGE and the protein levels of $\mathrm{CHOP}$ and $\beta$-actin were detected by Western blot analysis. The protein level of $\mathrm{CHOP}$ in $\mathrm{C}$ and $\mathrm{D}$ was quantified by densitometry and normalized to the level of $\beta$-actin. The fold increase was calculated based on each data of vehicle (first lane). ${ }^{*} P<0.05$ when compared with untreated control cells. ${ }^{\#} P<$ 0.05 when compared with TG- or BFA-treated cells in the absence of baicalein at each incubation time. (E) Cells were pretreated with $10 \mu \mathrm{M}$ SB203580 (SB) for $1 \mathrm{~h}$ and then treated with vehicle, $5 \mu \mathrm{M}$ TG, or $10 \mu \mathrm{M}$ $\mathrm{BFA}$ for $12 \mathrm{~h}$. Cell lysates were immunoprecipitated with anti-CHOP antibody and the immunoprecipitates were analyzed by Western blotting using anti-phospho-serine antibody and anti-CHOP antibody. reduced the TG- or BFA-induced ROS accumulation at all measured times (Figure 6A). This result suggests that baicalein has anti-oxidant effect on ER stress-induced ROS in HT22 cells.

We next examined the effects of two well-known anti-oxidants, $\mathrm{N}$-acetyl cysteine (NAC) and catalase on TG or BFA-induced ROS accumulation and compared that of baicalein. Our data showed that pretreatment with NAC $(5 \mathrm{mM})$ and catalase (5000 units) reduced TG- or BFA-induced ROS production more effectively than baicalein (Figure 6B). These results suggest that ER stress inducers TG and BFA produce intracellular ROS, particularly $\mathrm{H}_{2} \mathrm{O}_{2}$, in $\mathrm{HT} 22$ cells, and that baicalein reduces ER stress-induced ROS accumulation.

To understand the roles of ROS in ER stressinduced cell death, we examined the effect of NAC on ER stress-induced cytotoxicity as well as CHOP expression and caspase-12 activation. Similar to baicalein, NAC inhibited apoptotic cell death (Figure 6C) and blocked the expression of $\mathrm{CHOP}$ and the cleavage of caspase-12 in TG- or BFA-treated HT22 cells (Figure 6D and 6E).

We also examined whether ROS affect early ER stress response such as elF $2 \alpha$ phosphorylation by using NAC. The results showed that NAC reduced TG or BFA-induced elF2 $\alpha$ phosphorylation (Figure $6 \mathrm{~F}$ and $6 \mathrm{G}$ ). This suggests that reduction of ROS inhibits early ER stress-associated unfolded protein responses in HT22 cells. Collectively, these results suggest that baicalein reduces cell death, CHOP expression, and caspase- 12 activation, presumably through anti-oxidant activity.

\section{Baicalein reduces ER stress-induced MMP in HT22 neuronal cells}

During ER stress, crosstalk between ER and mitochondria induces mitochondrial damage and enhances cell death (Hitomi et al., 2004; Arduino et al., 2009). As an indication of mitochondrial damage, we examined MMP using 3,3'-dihexyloxacarbocyanine iodide $\left(\mathrm{DiOC}_{6}\right)$ in cells that were pretreated with vehicle or $50 \mu \mathrm{M}$ baicalein and then treated with $5 \mu \mathrm{M}$ TG or $10 \mu \mathrm{M}$ BFA for 2-6 h. As a positive control for reduction of MMP, the effects of $10 \mu \mathrm{M}$ rotenone, an inhibitor of mitochondrial complex I, on MMP were also examined. Treatment with TG or BFA resulted in almost no reduction in MMP levels at $2 \mathrm{~h}$ (data not shown), but led to a significant $\left({ }^{*} P<0.01\right)$ reduction at $6 \mathrm{~h}$ (Figure $7 \mathrm{~A}$ and $7 \mathrm{~B}$ ). However, pretreatment with baicalein recovered TG-, BFA-, or rotenone-induced MMP reduction. Similar to the effect of baicalein, NAC reduced TG- or BFA-induced MMP reduction in HT22 cells, suggesting the involvement of ROS in 
A

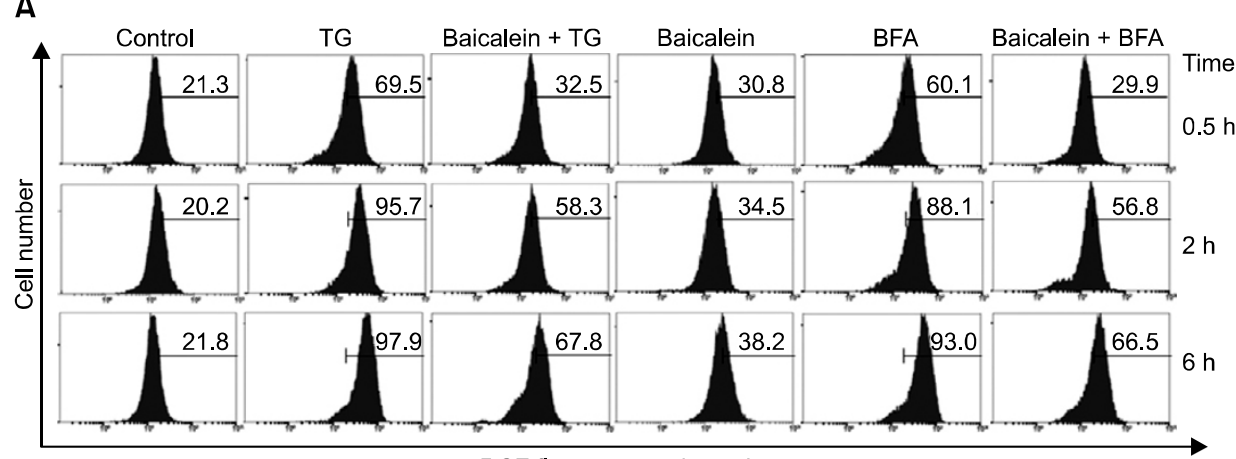

DCF fluorescence intensity

B

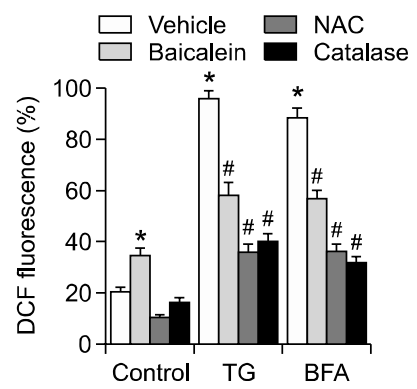

C

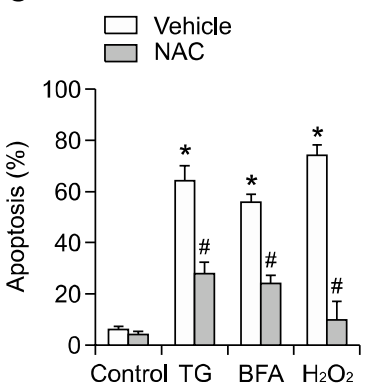

D

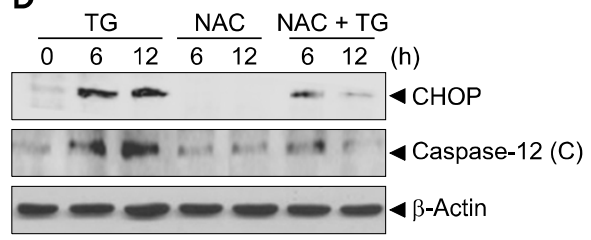

$\mathbf{F}$

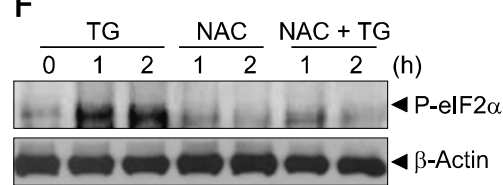

E

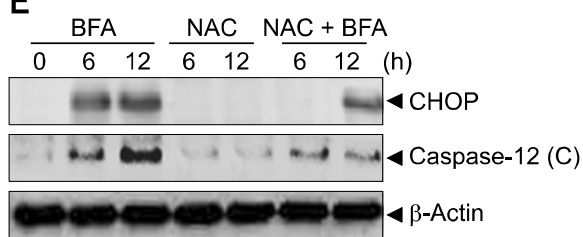

G

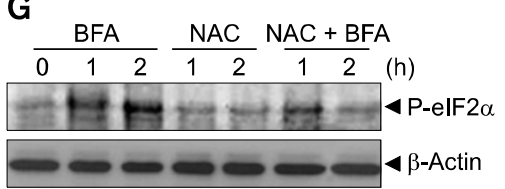

Figure 6. Effects of baicalein and anti-oxidants on ER stress-induced ROS accumulation, cell viability, CHOP expression, caspase-12 activation, and elF2 $\alpha$ phosphorylation in HT22 neuronal cells. (A) HT22 cells were preincubated with baicalein $(50 \mu \mathrm{M})$ for $1 \mathrm{~h}$ and treated with $5 \mu \mathrm{M}$ TG or $10 \mu \mathrm{M}$ BFA for the indicated times $(0.5,2,6$ h). Cells were then treated with $10 \mu \mathrm{M}$ DCF-DA for $30 \mathrm{~min}$ and DCF fluorescence was measured by flow cytometry as described in the Materials and Methods section. The percent ROS generation was calculated from DCF fluorescence. (B) HT22 cells were preincubated with baicalein $(50 \mu \mathrm{M})$ or anti-oxidants (5 mM NAC or 5000 units catalase) for $1 \mathrm{~h}$ and treated with $5 \mu \mathrm{M}$ TG or $10 \mu \mathrm{M}$ BFA for $2 \mathrm{~h}$. Cells were then treated with $10 \mu \mathrm{M}$ DCF-DA for 30 $\mathrm{min}$, and DCF fluorescence was measured by flow cytometry. The percent ROS generation was calculated from DCF fluorescence and plotted as the means \pm standard deviation of at least three experiments. ${ }^{*} P<0.01$ when compared with untreated control cells. ${ }^{\sharp} P<0.01$ when compared with TG- and BFA-treated cells without baicalein, NAC, or catalase, respectively. (C) HT22 cells were preincubated with $5 \mathrm{mM} \mathrm{NAC}$ for $1 \mathrm{~h}$, and treated with vehicle (Control), $5 \mu \mathrm{M} \mathrm{TG}, 10 \mu \mathrm{M} \mathrm{BFA}$, or $100 \mu \mathrm{M} \mathrm{H}_{2} \mathrm{O}_{2}$ for $24 \mathrm{~h}$, stained with $\mathrm{PI}$, and then evaluated by flow cytometry. The percent apoptotic sub-G1 fractions were plotted as the means \pm standard deviation of at least three experiments. ${ }^{*} P<0.01$ when compared with untreated control cells. ${ }^{\#} P<0.01$ when compared with TG, BFA, or $\mathrm{H}_{2} \mathrm{O}_{2}$-treated cells without NAC. (D-G) HT22 cells were preincubated with $5 \mathrm{mM} \mathrm{NAC}$ for $1 \mathrm{~h}$, and treated with $5 \mu \mathrm{M}$ TG (D, F) or $10 \mu \mathrm{M}$ BFA (E, G) for the indicated times, the cell lysates were separated by SDS-PAGE, and protein levels of CHOP, cleaved caspase-12 (C), phospho-elF2 $\alpha$ (P-elF2 $\alpha$ ), and $\beta$-actin were detected by Western blot analysis. 


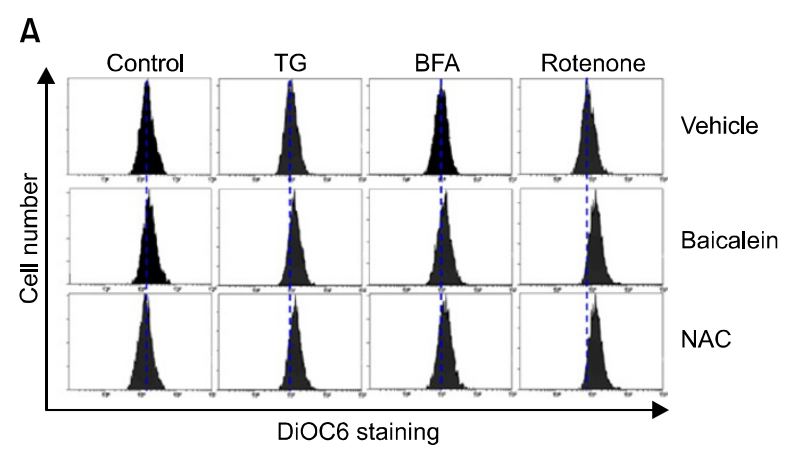

B

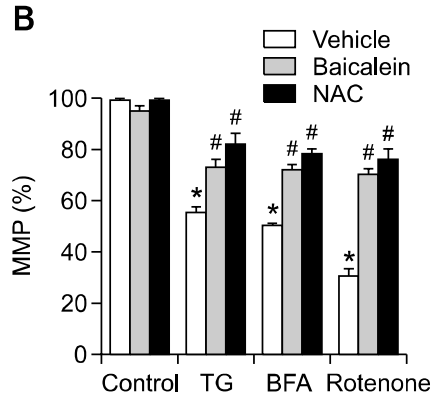

Figure 7. Effects of baicalein on ER stress-induced reduction of MMP in HT22 neuronal cells. HT22 cells were pretreated with $50 \mu \mathrm{M}$ baicalein or $5 \mathrm{mM} \mathrm{NAC}$, and treated with $5 \mu \mathrm{M} \mathrm{TG}, 10 \mu \mathrm{M} \mathrm{BFA}$, or $10 \mu \mathrm{M}$ rotenone for $6 \mathrm{~h}(\mathrm{~A}, \mathrm{~B})$. The cells were then stained with $\mathrm{DiOC}_{6}$ and the fluorescence was detected by flow cytometry as described in the Materials and Methods section (A). Percent MMP was calculated and plotted in the graph (B). ${ }^{*} P<0.01$ when compared with untreated control cells. ${ }^{*} P<$ 0.01 when compared with TG-, BFA-, or rotenone-treated cells without baicalein or NAC.

ER stress-induced MMP collapse. Collectively, these results suggest that ROS are involved in ER stress-associated mitochondrial dysfunction in HT22 cells and that baicalein protects HT22 cells by preventing TG- and BFA-induced mitochondrial damage through anti-oxidant activity.

\section{Discussion}

ER stress-induced apoptosis is a key pathologic event in neurological disease processes and neuronal cell death (Boyce and Yuan, 2006; Lindholm et al., 2006; Arduino et al., 2009). In the present study, we showed that baicalein reduced the apoptotic cell death of hippocampal neuronal HT22 cells induced by TG and BFA, and that an antiapoptotic effect of baicalein is associated with its anti-oxidant effect. Baicalein and baicalin, a glycosidic derivative of baicalein, are two main flavonoid components of $S$. baicalensis extract. Unlike baicalein, baicalin did not show a protective effect against ER stress-induced apoptosis (data not shown). We also found that baicalin was not able to reduce ER stress-induced ROS accumulation (data not shown). In agreement with our result, it was shown that the anti-oxidant potential of baicalin was attenuated as compared to that of baicalein (Chang et al., 2007). Moreover, it was also shown that cell permeability of baicalin was poor due to its glycoside group (Dai et al., 2008). Thus, differences of baicalein and baicalin in anti-oxidant potential and in cell permeability might contribute to their differential cytoprotective effects against ER stress-inducers.

Baicalein at a concentration of $50 \mu \mathrm{M}$ has been shown to increase the ROS levels and loss of MMP and apoptosis in N18 ganglion cells (Li et al., 2009). Induction of apoptotic death by baicalein was also observed at $100 \mu \mathrm{M}$ concentration in HL60 cells (Wang et al., 2004). Because baicalein caused elevation of intracellular $\mathrm{H}_{2} \mathrm{O}_{2}$ level, and catalase effectively blocked baicalein-induced DNA fragmentation, it was suggested that baicalein might trigger an apoptotic death program through ROS-mediated mitochondrial dysfunction pathway (Wang et al., 2004). In this study, we also observed a minor but significant increase in the basal ROS level in baicalein alone-treated HT22 cells (Figure $6 \mathrm{~A}$ and $6 \mathrm{~B}$ ), indicating that baicalein is a prooxidant. In addition, baicalein alone slightly induced MMP reduction (Figure 7) and apoptosis in HT22 cells (Figure 1B and $1 \mathrm{C}$ ). The physiological effect of ROS may depend on the level of ROS and the cell types. However, interestingly, we found that pretreatment with baicalein attenuated TG- or BFA-induced ROS accumulation (Figure 6A and $6 \mathrm{~B}$ ) and MMP reduction (Figure 7). This result is in agreement with that of a previous report showing that baicalein is a potent anti-oxidant against cardiomyocytes ischemia/reperfusion injury (Chang et al., 2007). Therefore, we suggest that baicalein exerts an anti-oxidative effect against TG- or BFAinduced mitochondrial dysfunction and apoptosis.

Moreover, in agreement with a recent report showing that baicalein induces ER stress ( $\mathrm{Li}$ et al., 2009), in this study, we observed changes in some of the ER stress-associated proteins including CHOP expression by baicalein in HT22 cells (Figure 3), although to a lesser degree than TG or BFA. However, interestingly, baicalein reduced TGor BFA-induced unfolded protein responses such as expression of CHOP and GRP78, spliced form of XBP-1, cleavage of ATF-6, and phosphorylation of elF2 $\alpha$ (Figure 3 ). Baicalein also inhibited ER stress-associated phosphorylation of MAPKs (Figure 4), accumulation of ROS (Figure 6A), collapse of MMP (Figure 7), and activation of caspases such as caspase-12 and -3 (Figure 2), 
which led to apoptotic cell death (Figure 1). The pro-oxidant effect of baicalein might explain the small but significant enhancement of unfolded protein responses, while its anti-oxidant effect might explain the inhibitory actions on changes in ER stress-associated proteins and apoptosis.

Baicalein's cytoprotective action could be explained by its direct free radical quenching effects against cytotoxicity and genotoxicity (Gao et al., 1999). Baicalein attenuated oxidant stress in a cardiomyocyte model of ROS generation during ischemia-reperfusion (Shao et al., 2002). Baicalein has also been shown to inhibit $\mathrm{H}_{2} \mathrm{O}_{2}$-induced apoptosis by induction of heme oxygenase-1 expression (Lin et al., 2007). Thus, it still remains to be determined whether or not the cytoprotective effects of baicalein on ER stress in HT22 cells are due to direct free radical scavenging activity or the activation of other anti-oxidant system.

Several studies have shown the involvement of p38 and JNK activation in ER stress-induced cytotoxicity (Wang and Ron, 1996; Urano et al., 2000; Yang et al., 2007). Activated JNK and p38 have been shown to increase expression and/or transcriptional activity of $\mathrm{CHOP}$ and hence its proapoptotic activity (Oyadomari and Mori, 2004; Kim et al., 2008). As expected, the JNK inhibitor SP600125 reduced TG- and BFA-induced CHOP expression (Figure 5C and 5D) and protected HT22 neuronal cells against apoptotic death (Figure 5A). However, the p38 inhibitor SB203580 blocked TG- and BFA-induced serine phosphorylation of CHOP but not its expression (Figure $5 \mathrm{C}-5 \mathrm{E})$, while it resulted in a significant reduction of TG- and BFA-induced cell death (Figure 5A). In agreement with our result, p38 has been shown to increase the transcriptional activity of $\mathrm{CHOP}$, but not its expression level, resulting in cell death (Wang and Ron, 1996).

Similarly, we also found that TG- or BFA-induced CHOP expression was abrogated by ERK inhibition following PD98059 treatment (Figure 5C and 5D) and the ERK inhibitor affected TG- and BFAinduced cell death (Figure 5A). Results showing the involvement of ERK in ER stress-induced cell death are in agreement with findings from a previous report on TG- or BFA-treated SH-SY5Y human neuroblastoma cells (Arai et al., 2004). We also performed experiments to determine whether these inhibitors of MAPKs worked properly by analyzing phosphorylation of $\mathrm{p} 38$, JNK, and ERK. The inhibitors, SB203580 and SP600125, effectively and selectively inhibited phosphorylation of p38 and JNK (c-Jun), respectively. However, PD98059 effectively inhibited ERK phosphorylation, and also had a tendency of inhibiting p38 phosphorylation (data not shown). Further studies are necessary to examine any possible cross-talks between the p38 and ERK pathways during ER stress in HT22 cells by using molecular and pharmacological means. Collectively, these data suggest that $\mathrm{p38}$, JNK, and ERK are involved in TG- or BFA-induced cell death through an increase in either CHOP expression or its transcriptional activity in HT22 cells.

Baicalein inhibited elF2 $\alpha$ phosphorylation and subsequent $\mathrm{CHOP}$ expression (Figure 3 ), suggesting that the elF $2 \alpha$ and $\mathrm{CHOP}$ pathway mediates baicalein's cytoprotective effect against ER stress. However, the role of PERK-induced elF2 $\alpha$ phosphorylation in cell death is currently unclear. Since PERK mutant cells were unable to survive ER stress, PERK-induced elF2 $\alpha$ phosphorylation has been suggested to play a role in reducing the work load imposed on the folding machinery during ER stress (Harding et al., 2000). Because NAC abrogated TG- and BFA-induced elF2 $\alpha$ phosphorylation (Figure 6F and 6G), ROS might play a role in the early ER stress response including phosphorylation of elF2 $\alpha$.

Taken together, we conclude that baicalein inhibits ER stress-induced apoptosis by reducing ROS accumulation, mitochondrial dysfunction, and CHOP induction in HT22 cells. Because ER stress has increasingly come into focus as a factor contributing to neuronal injury, further understanding of the mechanisms involved in the protective effects of baicalein against ER stress may significantly enhance the agent's pharmaceutical potential for use in treatment of neurodegenerative disease.

\section{Methods}

\section{Materials}

Dulbecco's modified Eagle's medium (DMEM), fetal bovine serum (FBS), and other cell culture products were purchased from Life Technologies (Grand Island, NY). TG and BFA were obtained from Biomol Research Labs (Plymouth Meeting, PA). Baicalein, 3-(4,5-dimethylthiazol-e-yl)-2,5-diphenyltetrazolium bromide (MTT), NAC, propidium iodide $(\mathrm{PI})$, DCF-DA, catalase, and $\mathrm{DiOC}_{6}$ were obtained from Sigma-Aldrich (St. Louis, MO). Antibodies against $\mathrm{CHOP}$, GRP78, XBP-1, ATF-6 $\alpha$, p38, JNK1, ERK, and elF2 $\alpha$, HRP-conjugated anti-goat and anti-rabbit secondary antibodies, and siRNAs of CHOP and scrambled control were purchased from Santa Cruz Biotechnology (Santa Cruz, CA). Antibodies against caspase-12, caspase-3, PARP, phospho-elF2 $\alpha$, phospho-p38, phospho-JNK, and phospho-ERK were obtained from Cell Signaling Technology (Beverly, MA). SB203580, SP600125, and PD98059 were purchased from Tocris (Bristol, UK). Enhanced chemiluminescence $(E C L)$ system was acquired from Amersham (GE Health care, Piscataway, NJ). 


\section{Cell culture}

The mouse hippocampal HT22 cell line is immortalized with a SV40 antigen but express neuronal properties (Lendahl and McKay, 1990; Fukui et al., 2009). HT22 cells were cultured in DMEM supplemented with $10 \%(\mathrm{v} / \mathrm{v})$ FBS, $100 \mathrm{U} / \mathrm{ml}$ penicillin, and $100 \mu \mathrm{g} / \mathrm{ml}$ streptomycin in a humidified $5 \%(\mathrm{v} / \mathrm{v}) \quad \mathrm{CO}_{2}$ incubator at $37^{\circ} \mathrm{C}$. For the experiments, after serum starvation for $3 \mathrm{~h}$, cells were preincubated with baicalein, baicalin, or NAC for $1 \mathrm{~h}$, and followed by treatment with $5 \mu \mathrm{M}$ TG or $10 \mu \mathrm{M}$ BFA for the indicated times.

\section{MTT assay}

Cell viability was determined as described based on conversion of MTT to MTT-formazan by mitochondrial enzymes as follows. Briefly, cells were seeded into a 12 -well plate at a density of $4 \times 10^{5}$ cells/well in growth medium and cultured to about $60-70 \%$ confluency, prior to the initiation of experimental treatment. After serum starvation for $3 \mathrm{~h}$, cells were treated with various concentrations of baicalein or $5 \mathrm{mM} \mathrm{NAC}$ for $1 \mathrm{~h}$. In certain experiments, cells were preincubated with $50 \mu \mathrm{M}$ baicalein for 1 $\mathrm{h}$ and then treated with $5 \mu \mathrm{M}$ TG or $10 \mu \mathrm{M}$ BFA. After $24 \mathrm{~h}$ of incubation at $37^{\circ} \mathrm{C}$, cells were washed three times with PBS and $30 \mu$ of MTT solution ( $5 \mathrm{mg} / \mathrm{ml}$ stock) was added to the cells, and they were then incubated for $1 \mathrm{~h}$ at $37^{\circ} \mathrm{C}$. The medium was removed carefully and $300 \mu$ of dimethyl sulfoxide was then added to resolve the blue formazan in living cells. Finally, the absorbance at $540 \mathrm{~nm}$ was read with an ELISA reader (Multiskan EX, Thermo Lab systems, Beverly, MA).

\section{Western blot analysis}

After treatment, cells were washed twice with ice-cold PBS, and the total cell lysates were prepared in lysis buffer containing $50 \mathrm{mM}$ Tris- $\mathrm{HCl}(\mathrm{pH} 7.4), 150 \mathrm{mM} \mathrm{NaCl}, 1 \%$ Triton X-100, $50 \mathrm{mM} \mathrm{NaF}, 5 \mathrm{mM}$ sodium pyrophosphate, 1 mM EDTA, $1 \mathrm{mM}$ EGTA, $1 \mathrm{mM}$ DTT, $0.1 \mathrm{mM}$ PMSF, and $0.5 \%$ protease inhibitor cocktail. Next, the whole cell lysates were centrifuged $\left(12,000 \times g\right.$ for $10 \mathrm{~min}$ at $\left.4^{\circ} \mathrm{C}\right)$ to remove cellular debris. The protein concentration was then determined by the Lowry method using a Bio-Rad DC protein assay kit. Cell lysates containing equal amounts of protein $(50 \mu \mathrm{g})$ were resolved by $8-10 \%$ SDS-polyacrylamide gel electrophoresis and then transferred onto Millipore nitrocellulose membranes. Next, the blots were blocked with a solution containing $5 \%$ skim milk in Tris-buffered saline with $0.05 \%$ Tween 20 (TBST) for $1 \mathrm{~h}$ at room temperature, and treated with primary antibodies $(1: 2,000)$ in TBST overnight at $4^{\circ} \mathrm{C}$, washed for $1 \mathrm{~h}$ with TBST, and further probed with secondary HRP-conjugated anti-rabbit, anti-mouse, or anti-goat IgGs $(1: 2,000)$ in TBST for $1 \mathrm{~h}$ at room temperature. The immune complexes were visualized using an ECL detection system according to the manufacturer's protocols.

\section{Flow cytometry for DNA content}

For detection of apoptotic cell death, HT22 cells were preincubated with $50 \mu \mathrm{M}$ baicalein or baicalin for $1 \mathrm{~h}$, and then treated with $5 \mu \mathrm{M}$ TG or $10 \mu \mathrm{M}$ BFA. After incubation for $24 \mathrm{~h}$, the cells were harvested, washed twice with phosphate-buffered saline (PBS), and then fixed with ice-cold $75 \%$ ethanol at $4^{\circ} \mathrm{C}$ for $24 \mathrm{~h}$. The cells were subsequently pelleted by centrifugation at $1,000 \mathrm{~g}$ for $5 \mathrm{~min}$ and the ethanol layer was discarded. After washing with PBS, the fixed cells were treated with $0.5 \mu \mathrm{g} / \mathrm{ml}$ RNase A in PI buffer for $30 \mathrm{~min}$. At the end of treatment, the cells were stained with PI $(20 \mu \mathrm{g} / \mathrm{ml})$ for $30 \mathrm{~min}$ in the dark. The cell cycle was then analyzed for DNA contents using Kaluza flow cytometry software (Beckman Coulter, Orange County, CA).

\section{RNA interference (siRNA)}

Predesigned siRNA against mouse CHOP, caspase-12 and control scrambled siRNA were purchased from Santa Cruz Biotechnology. The knock-down experiments with siRNA were carried out by plating $1 \times 10^{5}$ cells in 12-well plates or $0.25-0.4 \times 10^{6}$ cells in 6 -well plates overnight before transfection with $40 \mathrm{nM}$ siRNA using GeneSilencer ${ }^{\mathbb{R}}$ siRNA Transfection Reagent (Genlantis, Inc) according to the manufacturer's instructions. Cells were then cultured in normal growth medium for $24 \mathrm{~h}$ prior to drug treatment. Interference (knock-down) of CHOP or caspase-12 protein expression was confirmed by Western blot analysis using CHOP or caspase-12 antibody and scrambled siRNA was used as a control.

\section{Measurement of ROS production}

To measure ROS production, cells were preincubated with $50 \mu \mathrm{M}$ baicalein for $1 \mathrm{~h}$, followed by treatment with $5 \mu \mathrm{M}$ TG or $10 \mu \mathrm{M}$ BFA for 0.5-6 h, and incubation with $10 \mu \mathrm{M}$ DCF-DA for $30 \mathrm{~min}$. The cells were then washed twice with ice-cold PBS followed by suspension in the same buffer. Fluorescence intensity was measured by flow cytometry (Beckman Coulter) using excitation and emission wavelengths of 488 and $525 \mathrm{~nm}$, respectively. Ten thousand events were analyzed per sample.

\section{Immunoprecipitation}

After treatment, HT22 cells were lysed using lysis buffer (50 mM Tris- $\mathrm{HCl}, \mathrm{pH} 7.4,150 \mathrm{mM} \mathrm{NaCl}, 1 \%$ Triton X-100, $50 \mathrm{mM}$ NaF, $5 \mathrm{mM}$ sodium pyrophosphate, $1 \mathrm{mM}$ EDTA, 1 mM EGTA, $1 \mathrm{mM}$ DTT, $0.1 \mathrm{mM}$ PMSF, and $0.5 \%$ protease inhibitor cocktail) and then centrifuged at $13,000 \mathrm{rpm}$ for 10 $\min$ at $4^{\circ} \mathrm{C}$. The cell lysates were pre-cleared with protein A-Sepharose (Sigma) by incubation for $2 \mathrm{~h}$ at $4^{\circ} \mathrm{C}$ with constant agitation. The pre-cleared lysates were then incubated for $2 \mathrm{~h}$ with the appropriate antibody and protein A-Sepharose at $4^{\circ} \mathrm{C}$. The immunoprecipitates were washed three times in lysis buffer. The immunoprecipitation products were separated by $8 \%$ SDS-PAGE and then analyzed by Western blot using specific antibodies.

\section{Measurement of MMP}

To determine MMP, cells were preincubated with $50 \mu \mathrm{M}$ 
baicalein for $1 \mathrm{~h}$, followed by treatment with $5 \mu \mathrm{M}$ TG or 10 $\mu \mathrm{M}$ BFA for $6 \mathrm{~h}$. Cells were washed twice with PBS, resuspended in PBS containing $20 \mathrm{nM} \mathrm{DiOC}_{6}$ and $20 \mu \mathrm{g} / \mathrm{ml}$ $\mathrm{PI}$, and then incubated at $37^{\circ} \mathrm{C}$ for $15 \mathrm{~min}$. Fluorescence was observed in all cells at channel FL1 for $\mathrm{DiOC}_{6}$ or channel FL3 for PI. Non-apoptotic cells were stained green with $\mathrm{DiOC}_{6}$ and apoptotic cells showed decreased intensity of $\mathrm{DiOC}_{6}$ staining, while necrotic cells were stained red with PI. In addition, the cells were treated with $10 \mu \mathrm{M}$ rotenone as a positive control. Fluorescence intensity was then measured by flow cytometry (Beckman Coulter) using excitation and emission wavelengths of 482 and $504 \mathrm{~nm}$, respectively. At least twenty thousand events were analyzed per sample and each sample was analyzed in duplicate.

\section{Statistical analysis}

All data are presented as the mean \pm standard deviation of at least three independent experiments. Statistical comparisons were performed using one-way analysis of variance (ANOVA) followed by Tukey's post hoc test for multiple comparison (Graphpad Prism, version 5.0, Graphpad Software Inc, San Diego, CA). $P$ values of less than 0.05 were considered statistically significant.

\section{Acknowledgements}

This work was supported by a grant from Kyung Hee University (Year 2008).

\section{References}

Arai K, Lee SR, van Leyen K, Kurose H, Lo EH. Involvement of ERK MAP kinase in endoplasmic reticulum stress in SH-SY5Y human neuroblastoma cells. J Neurochem 2004; 89:232-9

Arduino DM, Esteves AR, Cardoso SM, Oliveira CR. Endoplasmic reticulum and mitochondria interplay mediates apoptotic cell death: relevance to Parkinson's disease. Neurochem Int 2009;55:341-8

Boyce M, Bryant KF, Jousse C, Long K, Harding HP, Scheuner D, Kaufman RJ, Ma D, Coen DM, Ron D, Yuan J. A selective inhibitor of elF2alpha dephosphorylation protects cells from ER stress. Science 2005;307:935-9

Boyce M, Yuan J. Cellular response to endoplasmic reticulum stress: a matter of life or death. Cell Death Differ 2006;13:363-73

Breckenridge DG, Germain M, Mathai JP, Nguyen M, Shore GC. Regulation of apoptosis by endoplasmic reticulum pathways. Oncogene 2003;22:8608-18

Calfon M, Zeng H, Urano F, Till JH, Hubbard SR, Harding HP, Clark SG, Ron D. IRE1 couples endoplasmic reticulum load to secretory capacity by processing the XBP-1 mRNA. Nature 2002;415:92-6

Chang WH, Chen CH, Gau RJ, Lin CC, Tsai CL, Tsai K, Lu FJ. Effect of baicalein on apoptosis of the human Hep $\mathrm{G} 2$ cell line was induced by mitochondrial dysfunction. Planta Med 2002;68:302-6

Chang WT, Shao ZH, Yin JJ, Mehendale S, Wang CZ, Qin Y, Li J, Chen WJ, Chien CT, Becker LB, Vanden Hoek TL, Yuan CS. Comparative effects of flavonoids on oxidant scavenging and ischemia-reperfusion injury in cardiomyocytes. Eur J Pharmacol 2007;566:58-66

Cho YM, Jang YS, Jang YM, Chung SM, Kim HS, Lee JH, Jeong SW, Kim IK, Kim JJ, Kim KS, Kwon OJ. Induction of unfolded protein response during neuronal induction of rat bone marrow stromal cells and mouse embryonic stem cells. Exp Mol Med 2009;41:440-52

Dai JY, Yang JL, Li C. Transport and metabolism of flavonoids from Chinese herbal remedy Xiaochaihu-tang across human intestinal Caco-2 cell monolayers. Acta Pharmacol Sin 2008;29:1086-93

Fukui M, Song JH, Choi J, Choi HJ, Zhu BT. Mechanism of glutamate-induced neurotoxicity in HT22 mouse hippocampal cells. Eur J Pharmacol 2009;617:1-11

Gao Z, Huang K, Yang X, Xu H. Free radical scavenging and antioxidant activities of flavonoids extracted from the radix of Scutellaria baicalensis Georgi. Biochim Biophys Acta 1999; 1472:643-50

Harding HP, Zhang Y, Bertolotti A, Zeng $H$, Ron D. Perk is essential for translational regulation and cell survival during the unfolded protein response. Mol Cell 2000;5:897-904

Hitomi J, Katayama T, Eguchi Y, Kudo T, Taniguchi M, Koyama Y, Manabe T, Yamagishi S, Bando Y, Imaizumi K, Tsujimoto Y, Tohyama M. Involvement of caspase-4 in endoplasmic reticulum stress-induced apoptosis and Abeta-induced cell death. J Cell Biol 2004;165:347-56

Hwang KY, Oh YT, Yoon H, Lee J, Kim H, Choe W, Kang I. Baicalein suppresses hypoxia-induced HIF-1alpha protein accumulation and activation through inhibition of reactive oxygen species and PI 3-kinase/Akt pathway in BV2 murine microglial cells. Neurosci Lett 2008;444:264-9

Jung SH, Kang KD, Ji D, Fawcett RJ, Safa R, Kamalden TA, Osborne NN. The flavonoid baicalin counteracts ischemic and oxidative insults to retinal cells and lipid peroxidation to brain membranes. Neurochem Int 2008;53:325-37

Kaufman RJ. Stress signaling from the lumen of the endoplasmic reticulum: coordination of gene transcriptional and translational controls. Genes Dev 1999;13:1211-33

Kim I, Xu W, Reed JC. Cell death and endoplasmic reticulum stress: disease relevance and therapeutic opportunities. Nat Rev Drug Discov 2008;7:1013-30

Kim R, Emi M, Tanabe K, Murakami S. Role of the unfolded protein response in cell death. Apoptosis 2006;11:5-13

Kim YO, Leem K, Park J, Lee P, Ahn DK, Lee BC, Park HK, Suk K, Kim SY, Kim H. Cytoprotective effect of Scutellaria baicalensis in CA1 hippocampal neurons of rats after global cerebral ischemia. J Ethnopharmacol 2001;77:183-8

Lee GH, Kim HK, Chae SW, Kim DS, Ha KC, Cuddy M, Kress C, Reed JC, Kim HR, Chae HJ. Bax inhibitor-1 regulates endoplasmic reticulum stress-associated reactive oxygen species and heme oxygenase-1 expression. J Biol Chem 


\section{7;282:21618-28}

Lee JH, Won SM, Suh J, Son SJ, Moon GJ, Park UJ, Gwag BJ. Induction of the unfolded protein response and cell death pathway in Alzheimer's disease, but not in aged Tg2576 mice. Exp Mol Med 2010;42:386-94

Lendahl U, McKay RD. The use of cell lines in neurobiology. Trends Neurosci 1990;13:132-7

Li YC, Lin HJ, Yang JH, Yang JS, Ho HC, Chang SJ, Hsai TC, Lu HF, Huang AC, Chung JG. Baicalein-induced apoptosis via endoplasmic reticulum stress through elevations of reactive oxygen species and mitochondria dependent pathway in mouse-rat hybrid retina ganglion cells (N18). Neurochem Res 2009;34:418-29

Lin HY, Shen SC, Lin CW, Yang LY, Chen YC. Baicalein inhibition of hydrogen peroxide-induced apoptosis via ROS-dependent heme oxygenase 1 gene expression. Biochim Biophys Acta 2007;1773:1073-86

Lindholm D, Wootz H, Korhonen L. ER stress and neurodegenerative diseases. Cell Death Differ 2006;13:385-92

Malhotra JD, Kaufman RJ. The endoplasmic reticulum and the unfolded protein response. Semin Cell Dev Biol 2007; 18:716-31

Oyadomari S, Mori M. Roles of CHOP/GADD153 in endoplasmic reticulum stress. Cell Death Differ 2004;11: 381-9

Pidgeon GP, Kandouz M, Meram A, Honn KV. Mechanisms controlling cell cycle arrest and induction of apoptosis after 12-lipoxygenase inhibition in prostate cancer cells. Cancer Res 2002;62:2721-7

Rao RV, Hermel E, Castro-Obregon S, del Rio G, Ellerby LM, Ellerby HM, Bredesen DE. Coupling endoplasmic reticulum stress to the cell death program. Mechanism of caspase activation. J Biol Chem 2001;276:33869-74

Schroder M, Kaufman RJ. The mammalian unfolded protein response. Annu Rev Biochem 2005;74:739-89

Shao ZH, Vanden Hoek TL, Qin Y, Becker LB, Schumacker PT, Li CQ, Dey L, Barth E, Halpern H, Rosen GM, Yuan CS. Baicalein attenuates oxidant stress in cardiomyocytes. Am J Physiol Heart Circ Physiol 2002;282:H999-H1006
Szegezdi E, Logue SE, Gorman AM, Samali A. Mediators of endoplasmic reticulum stress-induced apoptosis. EMBO Rep 2006;7:880-5

Telford WG, King LE, Fraker PJ. Comparative evaluation of several DNA binding dyes in the detection of apoptosisassociated chromatin degradation by flow cytometry. Cytometry 1992;13:137-43

Tirasophon W, Welihinda AA, Kaufman RJ. A stress response pathway from the endoplasmic reticulum to the nucleus requires a novel bifunctional protein kinase/ endoribonuclease (Ire1p) in mammalian cells. Genes Dev 1998;12:1812-24

Urano F, Wang X, Bertolotti A, Zhang Y, Chung P, Harding HP, Ron D. Coupling of stress in the ER to activation of JNK protein kinases by transmembrane protein kinase IRE1. Science 2000;287:664-6

Wang J, Yu Y, Hashimoto F, Sakata Y, Fujii M, Hou DX. Baicalein induces apoptosis through ROS-mediated mitochondrial dysfunction pathway in $\mathrm{HL}-60$ cells. Int $\mathrm{J}$ Mol Med 2004;14:627-32

Wang $X Z$, Ron D. Stress-induced phosphorylation and activation of the transcription factor CHOP (GADD153) by p38 MAP Kinase. Science 1996;272:1347-9

Wong BC, Wang WP, Cho CH, Fan XM, Lin MC, Kung HF, Lam SK. 12-Lipoxygenase inhibition induced apoptosis in human gastric cancer cells. Carcinogenesis 2001;22:134954

Yang G, Yang W, Wu L, Wang R. H2S, endoplasmic reticulum stress, and apoptosis of insulin-secreting beta cells. J Biol Chem 2007;282:16567-76

Yoshida H, Matsui T, Yamamoto A, Okada T, Mori K. XBP1 mRNA is induced by ATF6 and spliced by IRE1 in response to ER stress to produce a highly active transcription factor. Cell 2001;107:881-91

Zinszner H, Kuroda M, Wang X, Batchvarova N, Lightfoot RT, Remotti H, Stevens JL, Ron D. CHOP is implicated in programmed cell death in response to impaired function of the endoplasmic reticulum. Genes Dev 1998;12:982-95 